\title{
The Principles of Exchange Rate Determination in an International Finance Experiment
}

\section{Charles N. Noussair}

Purdue University

\section{Charles R. Plott}

California Institute of Technology

\section{Raymond G. Riezman}

University of Iowa

\begin{abstract}
This paper reports the first experiments designed to explore the behavior of economies with prominent features of international finance. Two "countries," each with its own currency, were created. International trade could take place only through the operation of markets for currency. The law of one price and the flow of funds theory of exchange rate determination were used to produce general equilibrium models that captured much of the behavior of the economies. Prices of goods, as well as the exchange rate, evolve over time toward the predictions of the models. However,
\end{abstract}

We wish to acknowledge the financial support of the National Science Foundation and the Caltech Laboratory for Experimental Economics and Political Science. The cooperation of the Center for Research in Experimental Economics and Political Decision-Making at the University of Amsterdam was important for the conduct of experiments in Amsterdam. We also wish to thank Mark Olson for his assistance with the Amsterdam experiments. The help of Hsing-Yang Lee with the electronic market programs made the study possible. An earlier version of this paper was presented at the Allied Social Sciences Association annual meetings in January 1994. We thank Marianne Baxter for her helpful suggestions as discussant of the paper, and Lars Peter Hansen for his helpful suggestions. 
both the law of one price and purchasing power parity can be rejected for reasons that do not appear in the literature. Patterns of international trade were as predicted by the law of comparative advantage.

\section{Introduction}

The interdependencies inherent in the structure of international financial flows and international economic activity motivated some of the earliest attempts to develop the basic principles of economics. The theorizing predated Adam Smith by decades and has been the subject of almost constant evolution during the intervening centuries. Principles of economic behavior were isolated by partial equilibrium theories and were integrated over the years to construct the general competitive model. The overriding power of this model to provide consistency in sets of ideas and theories cannot be denied, and, as such, it stands as a remarkable intellectual achievement. However, the accuracy of the model might be challenged in special applications, and the specific quantitative predictions of the model might not be testable in the complicated setting of the naturally occurring world.

The experiments reported below were designed to explore the ability of the competitive equilibrium model to predict and track prices and exchange rates. The experimental economies are extraordinarily complex and contain some of the complexities about which decades, if not centuries, of theorizing have grappled. Of course, they are simple relative to the naturally occurring economies to which the competitive model is frequently applied.

The experiments deal with two broad questions. First, to what extent does the competitive model help explain the behavior of an international economic system? Does the system behave at all as one would expect from the study of a set of equilibrium equations? While the experimental economies are simple relative to the naturally occurring ones, they are nevertheless economies in which several of the assumptions of the competitive model are violated to one degree or another. The model is constructed from many "partial equilibrium components," and if one part fails, the whole model fails. The question addressed is which parts, if any, seem to work. We find overall that the model works rather well, but certain parts of the model do not. For example, we find that the exchange rate converges strongly to the predicted equilibrium value (see result 1 ), but the prices in some of the commodity markets do not (see result 3 ). This 
is quite remarkable since the foreign exchange market is used only to facilitate trading in the underlying commodity markets. The overall result is very important since it demonstrates that many aspects of the price discovery process can be accurately described by simple equilibrium equations even if other aspects of the data are inconsistent with equilibrium behavior.

A second question, which is closely related to the first, is, Do we see the same types of failures of the model that are found in the field? Variables thought to cause the failure of the model in the field are not present. As will be reported in the paper, similar failures are observed in the experiments; therefore, the theory may fail to explain the data in the field as a result of much more fundamental causes than was previously thought. Specifically, we find in the experiments that the law of one price (LOP) and purchasing power parity (PPP) do not work well at all. As it turns out, LOP and PPP do not work well in the field either (Meese and Rogoff 1983; Kimbrough 1987; Krugman and Obstfeld 1994). The failure of LOP and PPP to explain the field data has been met by an avalanche of models and theories. ${ }^{1}$ This research has suggested a number of explanations for the failures of LOP and PPP to fit the data. Most prominent among them are the existence of governmental trade barriers and transportation costs, the presence of nontraded goods, imperfect competition, difficulties measuring national price indices accurately, and changes in the terms of trade. However, none of the factors suggested by this vast literature is present in our laboratory environments and therefore could not be responsible for the observed failures. This suggests that LOP and PPP could fail in the field as a result of more fundamental causes than has been previously supposed. Section VIII of the paper addresses this issue.

The paper is organized as follows. Section II describes the laboratory economies. The economic environments were designed to have a classical structure in which the competitive model could be naturally applied, with the equilibria easily computed and well separated from the predictions of other models in order that the results not be confused. The choice of design reflects practical difficulties associated with conducting complex experiments. Previous experimental results can be used as "baselines" of behavior, but the need to separate the predictions of various models is central to the design. Section III outlines the experimental design and procedures. The

\footnotetext{
${ }^{1}$ There has been an interest in the development of theoretical models that would produce departures from purchasing power parity as equilibrium phenomena (Sargent 1987; Grilli and Roubini 1992). However, the variables that can cause equilibrium departures in the models are not present in the actual economies we created.
} 
models are discussed in Section IV, and the predictions are highlighted in Section V. A special statistical methodology is in Section VI. The results are listed in Section VII. Section VIII analyzes the reasons for the failure of LOP and PPP. Section IX summarizes our conclusions.

\section{The Laboratory Economies}

The experimental setup is consistent with requiring a type of cashin-advance constraint, similar to that imposed by Lucas (1982). The parameters are set so that gains from exchange exist from international trade. That is, in the competitive equilibrium, foreign trade exists. However, the experimental environment requires that importers purchase foreign exchange in advance of their purchase of foreign goods. No agent is allowed to sell a good in a foreign country, so an agent cannot acquire foreign exchange by export and sale. Therefore, agents must acquire foreign exchange in advance of their purchases of foreign goods directly in the foreign exchange market. Of course, this activity creates a supply of home currency to the exchange market.

Two countries were indexed A and B. Each country produced two goods that were called $x$ and $y$. Each country had three buyers of $x$ and $y$ who were indifferent between the source of supply. That is, a consumer in A received the same utility from $x$ supplied from A as he received from $x$ supplied from $\mathrm{B}$, and similarly with $y$. Consequently, it will make sense to talk about a demand for and supply of $x$ at either the country level or the world level. In addition, each country had three suppliers, each of whom supplied both $x$ and $y$.

Buyers in each country had utility functions of the form U.S. dollars $=a\left[M_{c}-M_{0}+R_{x}(x)+R_{y}(y)\right]$, where $a$ is a scale factor; $M_{c}$ is the currency of the country in which the agent resides; $M_{0}$ is the initial endowment of the home currency; $x$ and $y$ are the consumption by the individual, measured in the units of the two commodities; and $R$ is denominated in terms of the home currency. Similarly, suppliers in a given country had an incentive function of the form U.S. dollars $=b\left[M_{c}-M_{0}-C_{x}(x)-C_{y}(y)\right]$, where $C$ is denominated in home currency units. All agents received a large initial endowment of home currency but had no endowment of foreign currency. Sellers received an endowment of $x$ and $y$, and $C_{x}(x)$ and $C_{y}(y)$ represented the cost of sale. Buyers received no initial endowment of either $x$ or $y$. Notice that individuals placed no value on the currency of the country in which they did not reside. So, this world had two countries with six agents in each, two commodities, and two currencies that had a value only to the agents of the home country. 
Preferences were induced such that the aggregate demand and supplies were approximated by the following equations:

$$
\begin{aligned}
& \text { country A: } x \text { demand: } 43-.75 x-p_{x}^{\mathrm{A}}=0, \\
& x \text { supply: } 2+2 x-p_{x}^{\mathrm{A}}=0, \\
& y \text { demand: } 65-3 y-p_{y}^{\mathrm{A}}=0, \\
& y \text { supply: } 11+1.5 y-p_{y}^{\mathrm{A}}=0 ; \\
& \text { country B: } \quad x \text { demand: } 925-45 x-p_{x}^{\mathrm{B}}=0, \\
& x \text { supply: } 127.5+15 x-p_{x}^{\mathrm{B}}=0, \\
& y \text { demand: } 2,646-36 y-p_{y}^{\mathrm{B}}=0, \\
& y \text { supply: } 150+180 y-p_{y}^{\mathrm{B}}=0 .
\end{aligned}
$$

The notation $p_{k}^{i}$ means the price of commodity $k$ that exists in country $i$. These functions are shown in figure 1 .

Constraints on trade were imposed to force the use of the international financial markets. First, all purchases and sales in a country had to be made in terms of the local currency. It was not possible to buy in a foreign country without having foreign currency first, and no agent was endowed with foreign currency. Second, no agent was allowed to export, but all agents could import. This meant that an agent who wanted to buy abroad could not sell abroad in order to get the exchange. The agent was required to go to the exchange market and purchase foreign currency with the home currency. Once purchases were made abroad, they could be transported to the home country without cost and either consumed or resold for home currency.

\section{Experimental Design and Procedures}

Four experiments were conducted. The subjects were students at the California Institute of Technology and the University of Amsterdam. Three sessions took place at the Laboratory for Experimental Economics and Political Science at Caltech, and one took place at the Center for Research in Experimental Economics and Political Decision-Making at the University of Amsterdam, in the Netherlands. A list of the experiments indexed by the date of the experiment can be found in table 1 .

The experiments were conducted in English, and the subjects were paid in U.S. dollars at Caltech and in Dutch guilders at Amsterdam. All the Amsterdam subjects had participated in one pilot experiment of this series previously. This was intended to acquaint them 


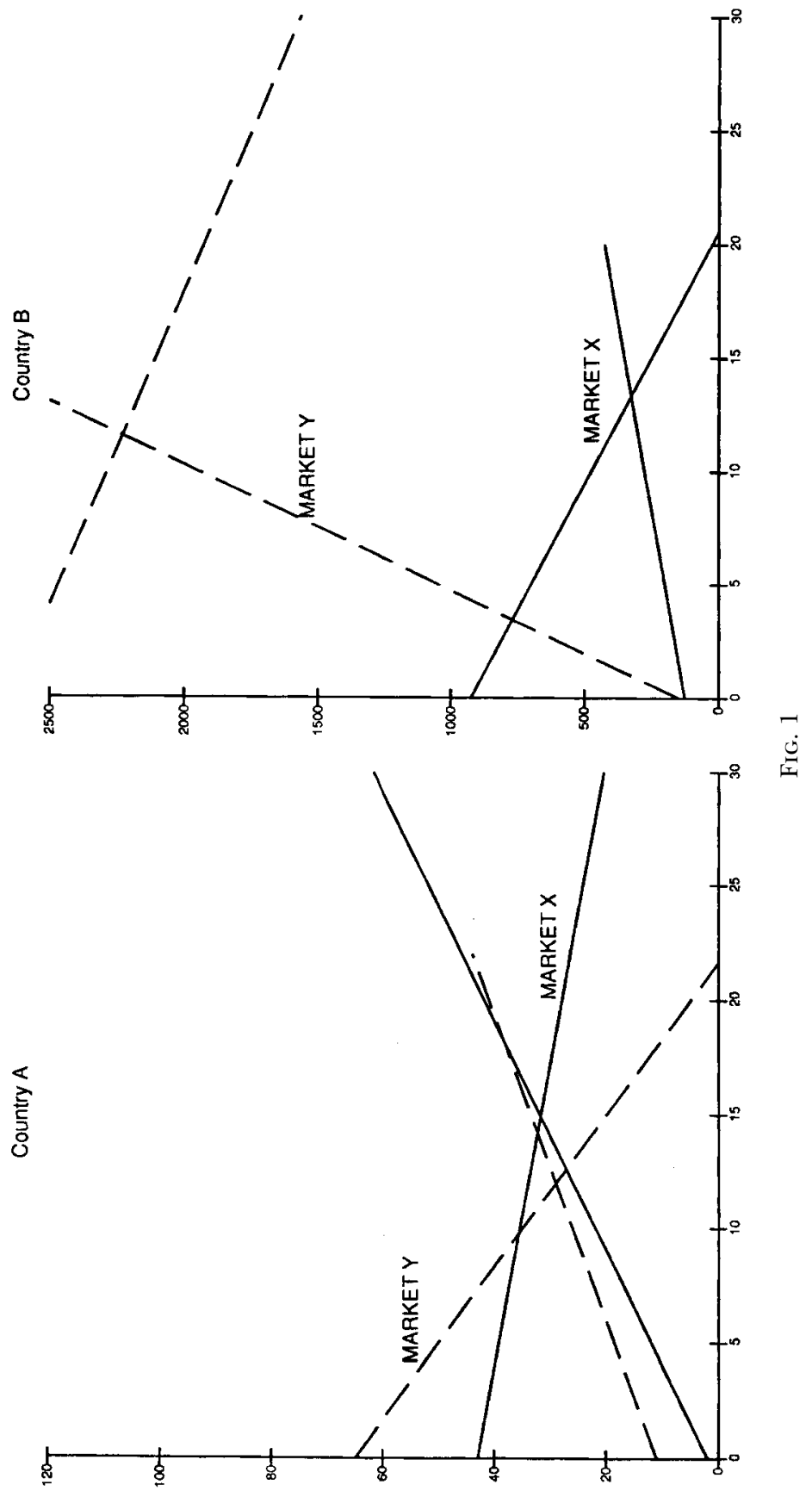


TABLE 1

EXPERIMENTS: LOCATION, SUbJeCTS, AND EXPERIENCE

\begin{tabular}{llclc}
\hline \hline Index* & \multicolumn{1}{c}{ Location } & $\begin{array}{c}\text { Number of } \\
\text { Subjects }\end{array}$ & Experience & $\begin{array}{c}\text { Number of } \\
\text { Periods }\end{array}$ \\
\hline 011393 & Caltech & 12 & General market & 10 \\
011493 & Caltech & 12 & General market & 10 \\
040793 & Univ. Amsterdam & 12 & 1 pilot experiment & 10 \\
042193 & Caltech & 12 & General market & 10 \\
\hline
\end{tabular}

* Index corresponds to the date on which the experiment was conducted.

with the accounting procedures, the computer keys, and the general setting in which the economic activity takes place in an experiment. The Caltech subjects had not participated in international finance experiments previously, but a substantial fraction of these subjects had been in other market experiments before.

At the beginning of each experimental session, subjects went through an interactive computerized instructional program that took about 30 minutes. This program gave them instructions about the keys and the other functions of the computer. ${ }^{2}$ Afterward, the experimenter read the specific instructions for this experiment aloud as the subjects followed along, reading from their own copy. Subjects were shown at the board an example of how to read a redemption value sheet and a cost schedule, the two sheets on which their incentive functions were displayed. They were also instructed on how to calculate their profits, which they were required to do on their end-of-period summary sheets. Examples of the written materials used can be found in the Appendix.

After the instruction was completed, the market was replicated 11 times, each replication constituting a period. Each was like a trading day, and each day was identical. The first period was used for practice and did not count toward subjects' cash earnings. Each individual kept the same "utility function" in each replication, although individuals' utility functions differed among agents. Thus the market environment was kept constant over the 10 periods following the practice period. All inventories of goods and currencies were reset at the same starting level each period. Nothing was carried over from period to period, except the earnings of the subjects.

In each of the experiments there were 12 subjects, six buyers and six sellers. There were three buyers and three sellers in each country.

${ }^{2}$ This program is part of the general multiple unit double auction (MUDA) program outlined in Plott (1991) and is contained in the diskette that accompanies the general market program used in the experiment. 
As a resident of a country, each agent was endowed with an inventory of his or her home currency, and only the home currency had value to him or her. Consumption and home currency cash had value in U.S. dollars or Dutch guilders, depending on the location of the experiment. The foreign currency had no value, except as a means of buying the goods abroad, which could then be consumed or sold for home currency.

The market mechanism employed was a modified version of the computerized MUDA. The program was modified to allow for multiple countries, represented by different pages on the computer screen. Each page (country) contained three markets in which all trades took place in terms of the local currency. The page also listed the amount of that country's cash that the subject had on hand, which could be used to buy in the markets in that country. Sales in that country added to the amount of that country's cash that the subject had on hand. The three markets allowed trading of $x, y$, and the currency of the other country. So purchases and sales in these markets, as well as the purchase and sale of the currency of the other country, were made in terms of the currency relevant to the page, and all bids and asks were quoted in terms of the currency of that page. When the subject changed pages to the other country, the cash on hand of the first page became the inventory of foreign currency on the second page, and the inventory of foreign currency on the first page became the cash on hand on the second page. This convention automatically enforced the requirement that all transactions in a country took place in terms of the currency of that country.

Any agent could transport goods from another country into his own, but no individual could transport to the foreign country directly. The MUDA program allows for transformations of inventory in one group of markets (one country) to another group of markets (another country), possibly on different pages on the computer. This feature was used to implement international transport. Purchases in a foreign country, made with the currency from that country, were automatically credited to the inventory of the commodity held by the subject in the foreign country. The inventory of that commodity could be costlessly transformed into the inventory of the same commodity in the subject's home country. Once in the home country, the commodity could be sold at home for cash or consumed. Thus imports were allowed but exports were not. That is, no individual could transform inventories held at home to the inventory of the same commodity held in the foreign country. This restriction was needed to force the use of the currency markets. If transportation in both directions had been allowed, the subject could have exported a commodity and sold it for foreign currency, which could 
have then been used to purchase commodities for import and sale at home without ever using the foreign currency markets. Since the operation of the currency market was considered to be a fundamental purpose of the experiment, steps were taken to make sure that such markets had a function and would thus be used.

\section{Models}

Two models are considered, competition and autarky. In the competitive model, agents make trades of commodities and corresponding purchases and sales of foreign exchange to permit these trades. There is no role for money, foreign or domestic, other than this transactions demand. Since the experimental agents receive payoffs for domestic (but not foreign) currency held at the end of each period, this is an economy in which demanders and suppliers have (domestic) money in their utility functions. In other words, the domestic money has commodity value, but not to foreigners.

The competitive outcome can be found by solving equations (1)(7) below. There is also a possibility that autarky will occur. That is, traders will choose not to engage in foreign trade. This is not an unreasonable notion, as one might believe at first glance, considering the risks of participating in the foreign exchange market and the complexity of international transactions.

\section{A. The Competitive Model}

The competitive model has three components. Home market demand and supply give four equations that require that materials balance and that incentives to buy and sell be equated at existing prices. The second set of equations, which we call purchasing power parity, can be viewed as nonarbitrage conditions. They require that prices in the two countries, adjusted for exchange rates, be the same. The final component requires equilibrium in the foreign exchange market, given the special definitions of market demand and market supply based on imports and exports. Of course, these three components can be viewed as partial equilibrium models independently of any general equilibrium implications.

\section{Home Market Demand and Supply}

The law of supply and demand in the home markets captures the idea that home prices are determined by local demand, plus exports in relation to local supply, plus imports. In essence, the principles of demand and supply operate independently of the origin, ultimate 
destination, or use of the commodities. The theory is captured by the following equations:

$$
\begin{aligned}
& D_{x}^{\mathrm{A}}\left(p_{x}^{\mathrm{A}}\right)=S_{x}^{\mathrm{A}}\left(p_{x}^{\mathrm{A}}\right)+\text { imports, } \\
& D_{y}^{\mathrm{A}}\left(p_{y}^{\mathrm{A}}\right)=S_{y}^{\mathrm{A}}\left(p_{y}^{\mathrm{A}}\right)-\text { exports, } \\
& D_{x}^{\mathrm{B}}\left(p_{x}^{\mathrm{B}}\right)=S_{x}^{\mathrm{B}}\left(p_{x}^{\mathrm{B}}\right)-\text { exports, }
\end{aligned}
$$

and

$$
D_{y}^{\mathrm{B}}\left(p_{y}^{\mathrm{B}}\right)=S_{y}^{\mathrm{B}}\left(p_{y}^{\mathrm{B}}\right)+\text { imports, }
$$

where $D_{j}^{L}$ and $S_{j}^{L}$ equal the quantity demanded and supplied, respectively, of $\operatorname{good} j$ in country $L$.

\section{Law of One Price and Purchasing Power Parity}

In contrast to the home market demand and supply, the LOP theory generalizes the idea of market clearing to extend across international boundaries. In the absence of tariffs, taxes, transportation costs, and other complicating factors, the theory asserts that the prices of the goods will be the same in both countries after prices are factored by the exchange rates. It is the LOP theory that can be interpreted as governing the flow of imports and exports in response to relative prices and the exchange rate.

Let $r$ be the exchange rate, that is, the price of currency A in terms of currency B. The equations for the LOP theory are

$$
r p_{x}^{\mathrm{A}}=p_{x}^{\mathrm{B}}
$$

and

$$
r p_{y}^{\mathrm{A}}=p_{y}^{\mathrm{B}} .
$$

Purchasing power parity theory is a similar relationship to (5) and (6) except that price indices are substituted for the prices of the goods. In Section VII we evaluate PPP using an appropriate price index for the experimental economy.

\section{Flow of Funds Theory}

It is the flow of funds theory that provides the final equation for exchange rate determination. Briefly, the theory is another way of saying that the exchange rate is determined by the demand for and supply of a currency. Formally the equation is

$$
\begin{aligned}
& \left(\text { demand for imports of } x \text { by A) } p_{x}^{\mathrm{B}}\right. \\
= & r(\text { demand for imports of } y \text { by } \mathrm{B}) p_{y}^{\mathrm{A}} .
\end{aligned}
$$


The left-hand side of the equation is the international demand for currency B that results from the country A purchases of $x$ from country B. Country A needs this amount of country B currency in order to make the purchases. The right-hand side of the equation is the supply of currency B in the international market. The imports of $y$ by country $\mathrm{B}$, when multiplied by the country A price of $y$, yield the total amount of country A currency that is needed by country B in order to purchase the imports. When multiplied by the exchange rate (the units of currency $B$ needed to purchase a unit of currency A), the quantity on the right-hand side of the equation becomes the international supply of currency B.

Care must be exercised in interpreting equation (7). First, because the exchange rate $r$ is measured in units of $\mathrm{B}$ per unit of $\mathrm{A}$, an increase in the price of currency $\mathrm{B}$ is a decrease in $r$. Second, unless operational definitions are selected carefully, equation (7) can acquire the properties of a tautology. In particular, if "actual imports" are substituted for the "demand for imports," if all international exchange is spent on foreign goods (no unused exchange and no currency speculation), and if $r$ is defined as an appropriate weighted average of transactions, then the equation must be satisfied by virtue of the definitions. In some of the analysis that follows, actual imports are used in the statistical analysis, so the degree to which the equation is not satisfied reflects the existence of speculation, wasted exchange, and the lack of appropriate weighting of individual transactions in the determination of the measure of $r$. The reader will be warned when this takes place.

Previous studies have consistently found that there is a strong tendency for double auction markets to converge to the competitive equilibrium with replication of the market period, even when there are multiple interdependent markets (Noussair, Plott, and Riezman 1995). However, the economy constructed here provides a very difficult test for the model. The cash-in-advance constraint and the existence of substantial international trade in the competitive equilibrium mean that importers must purchase foreign exchange for the model to predict correctly. Furthermore, agents must purchase enough foreign exchange to be able to import the competitive equilibrium amount of international trade and then sell all unused foreign exchange at the competitive equilibrium exchange rate.

\section{B. Autarky Model}

The autarky model is one alternative to the competitive model. It predicts that international trade will not take place; instead, the economies will operate as though they were in isolation. The model 
TABLE 2

Predicted Prices of the Competitive Equilibrium Model and the Autarky Model: Countries A and B, Commodities $x$ and $y$, and Exchange Rates of Currencies A ANd B

\begin{tabular}{|c|c|c|c|c|c|c|}
\hline \multirow[b]{3}{*}{ MODEL } & \multicolumn{3}{|c|}{ Country A } & \multicolumn{3}{|c|}{ Country B } \\
\hline & & & Currency & & & Currency \\
\hline & $x$ & $y$ & $\mathrm{~A} / \mathrm{B}$ & $x$ & $y$ & $\mathrm{~B} / \mathrm{A}$ \\
\hline Competitive equilibrium & 15 & 40 & $1 / 47$ & 682 & 1,888 & 47 \\
\hline Autarky & 32 & 29 & $\ldots$ & 327 & 2,230 & $\cdots$ \\
\hline
\end{tabular}

NotE.-Prices in the table (except for the price of currency B in country B) are the values of the solution to the continuous approximation of the experimental parameters rounded to the nearest integer.

should be taken seriously and not only as a benchmark. If the currency markets suffer from continuous disequilibrium, if the dynamics of adjustment are such that international trade is hazardous, if the transactions are too slow or fast, or if the market periods are too short, then international trade might not take place.

\section{Predictions}

Both the competitive and the autarky models predict the exact value of each of the variables in the system. That is, the models predict the prices in both countries and for all commodities, the exchange rate, the magnitude of imports and exports, and so forth. Some of these predictions are summarized in table 2.

The prediction of the competitive model is the solution to equations $(1)-(7)$. The prediction of the autarky model is the solution to equations $(1)-(4)$ with the value of all imports and exports constrained to be zero. The table displays the solutions to the equations rounded to the nearest integer. The exact demand and supply functions used in the experiment were discrete step functions that are approximated by the continuous functions listed in Section II and displayed in figure 1 .

\section{Statistical Methodology}

The application of statistical models to experimental market data is characterized by some classic problems. This section will facilitate an understanding of the methodology used in this paper and its possible limitations. Two problems appear not to have any good solution, given the current state of theory and estimation techniques, so all conclusions must be evaluated in light of the tenuous assumptions that are explicit and implicit in the statistical models. The first 
problem is that the models, such as the competitive model, make predictions of the magnitudes of a large number of variables. From an intuitive point of view, it is not surprising if the model fails on one or even several dimensions, but the statistical models that we have available are not forgiving of errors of any type.

The second problem occurs because the theoretical model is a static equilibrium model, whereas the data are clearly generated by a dynamic process. Furthermore, in simpler experiments the existence of a convergence phenomenon has been demonstrated on many occasions. Thus any statistical model must be sufficiently forgiving of the lack of theory of dynamics to allow some latitude for convergence.

The first problem is not addressed. Instead, each of the major predictions of a model is considered separately. Each variable is observed separately, and the question is posed about its magnitude in relation to the predictions of one or the other of the models.

The second problem is addressed by the application of a simple dynamic model. ${ }^{3}$ This model assumes that, for any particular dependent variable, each experiment may start from a different origin but all markets will experience adjustment, as described by a common functional form. Furthermore, the model assumes that the variable will converge to a common asymptote. Formally, the model is

$$
z_{i t}=B_{11} D_{1}\left(\frac{1}{t}\right)+\cdots+B_{1 k} D_{k}\left(\frac{1}{t}\right)+B_{2}\left(\frac{t-1}{t}\right)+u_{i t},
$$

where $i$ is the index of the experiment, $D_{j}$ are dummy variables that take the value one if $i=j$ and zero otherwise, $t$ is time measured in terms of the number of the experimental period, $k$ is the number of experiments, and $u$ is a random variable distributed normally with zero mean.

Notice that the statistical model has some useful properties. It allows for the possibility that variables may take different values at the start of different experiments. The terms $B_{1 i}$ measure these different origins of the data for the different experiments. The model then captures the specification that the experiments are converging to a common asymptote. During the early periods the asymptote gets no weight because the term $(t-1) / t$ is small; but as $t$ gets large, the term goes to one whereas $1 / t$ goes to zero. Thus the weight of the end of the experimental session is on the common term $B_{2}$.

Thus the model can be used to test the hypothesis that the data

\footnotetext{
${ }^{3}$ This model is called the Ashenfelter-El-Gamal model in Noussair et al. (1995), where it is first used.
} 
are converging to the predictions of various models by testing whether or not the estimates of $B_{2}$ are significantly different from the predictions of the models. In addition, a notion of partial convergence can be used to assess the models. Comparison of the $B_{1 j}$ terms with the $B_{2}$ term reveals the direction of convergence. If the $B_{2}$ term is closer to the model's prediction than the $B_{1 j}$ terms are, we say that the data are partially converging to the model's predictions. If the $B_{2}$ term is not significantly different from a model's prediction, we say that the variable is strongly converging to the prediction.

\section{Results}

Figures 2 and 3 contain time series for the two goods markets in each of the two countries for one of the experiments (experiment 042193). On the vertical axes are measured the prices in terms of the currency in which transactions took place. On the horizontal axes is measured the time in seconds at which actions occurred. These are the actual transaction price observations. Vertical lines indicate the start and end of periods. The data from the goods markets in country A are in figure 2 and the data from the goods markets in country B are in figure 3 . One horizontal line represents the value of the competitive equilibrium for the appropriate variable, and another indicates the prediction of the autarky model. Both lines are labeled accordingly. Figure 4 contains the time series of the exchange rate for all four experiments, which corresponds to the prices in the market for currency A in country B. In addition, a market was opened for currency B in country A. Since the MUDA program allows trading only at integer prices, at a competitive equilibrium price of $1 / 47$, activity in the market for currency $\mathrm{B}$ in country A quickly ceased in every experimental session.

The data in figures 2 and 3 are typical of all the experiments. The prices seem to be moving toward the competitive equilibrium prices, although there is substantial variation in prices within periods. Early in the experiments, the prices for $x$ in country A are higher than the competitive equilibrium levels, and the prices for $x$ in country $\mathrm{B}$ are lower than the competitive equilibrium levels. As can be seen in figure 4, near the end of all the experiments, the exchange rate is close to the competitive equilibrium, although it tends to be lower early in each of the sessions.

Estimates of the parameters of the statistical model are contained in table 3. The standard errors are in parentheses. Each variable is estimated separately. In addition, separate tests are developed from the equations that define PPP theory and flow of funds theory. These tests are also contained in the table. The standard errors are cor- 


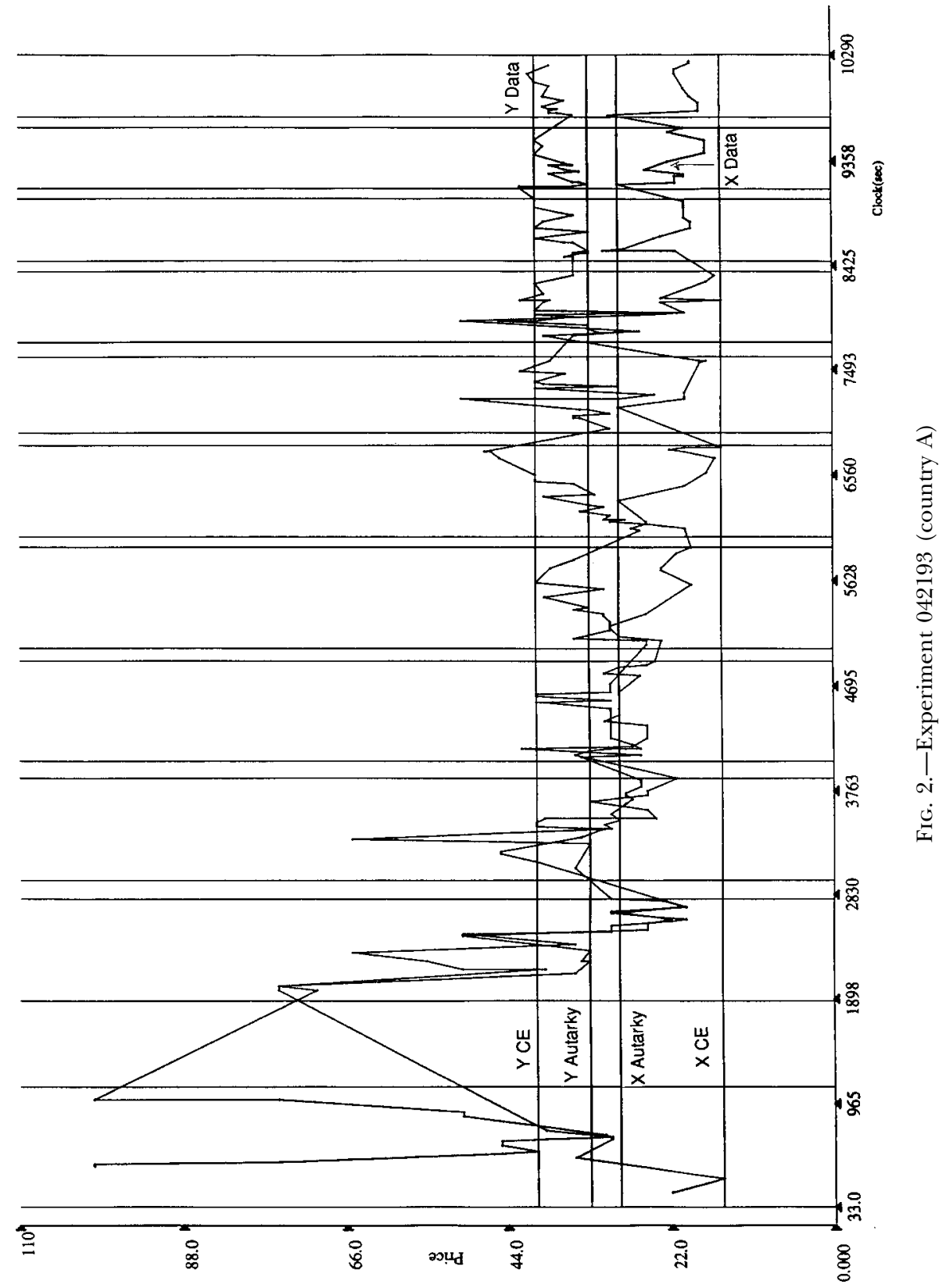




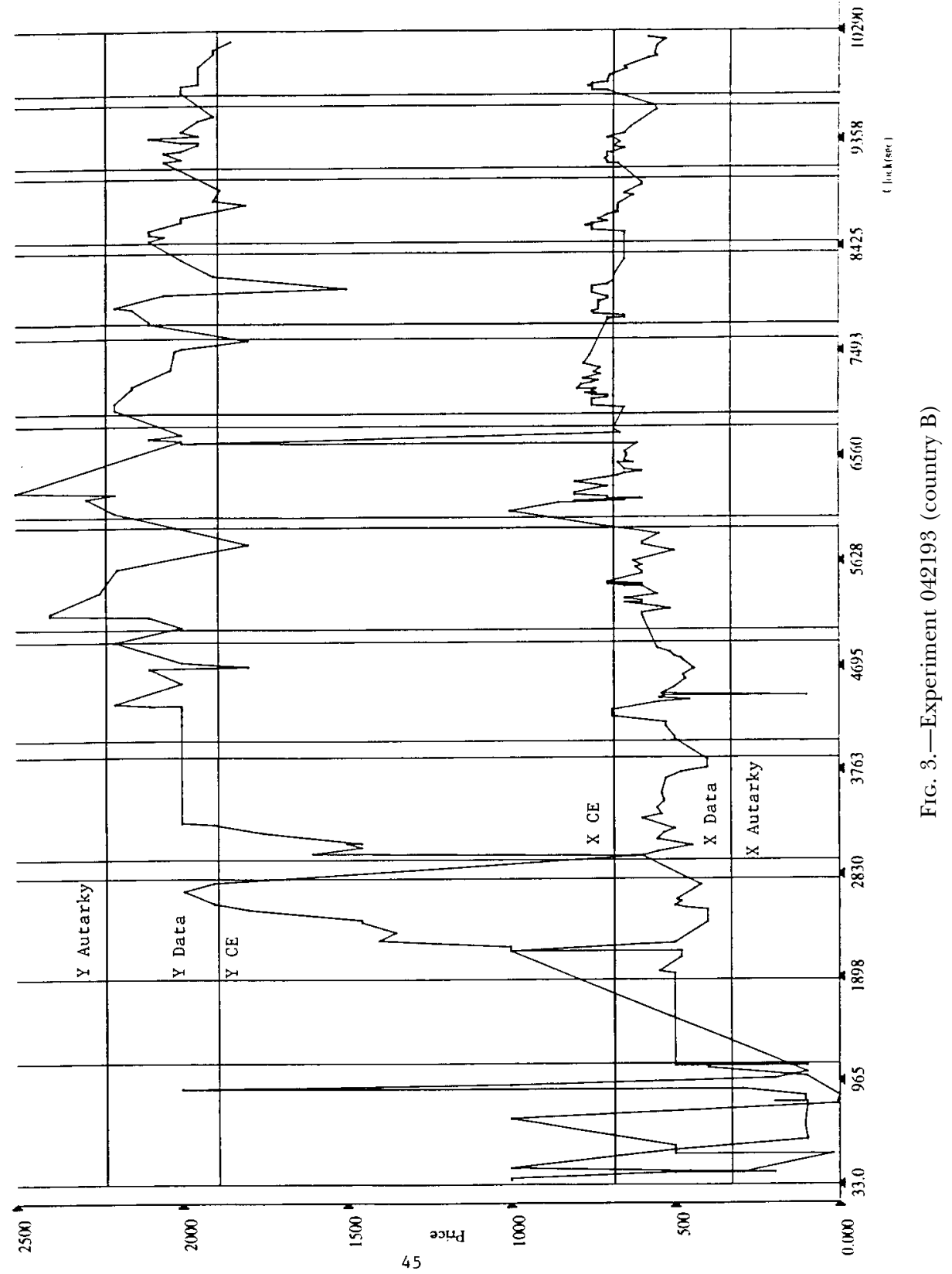




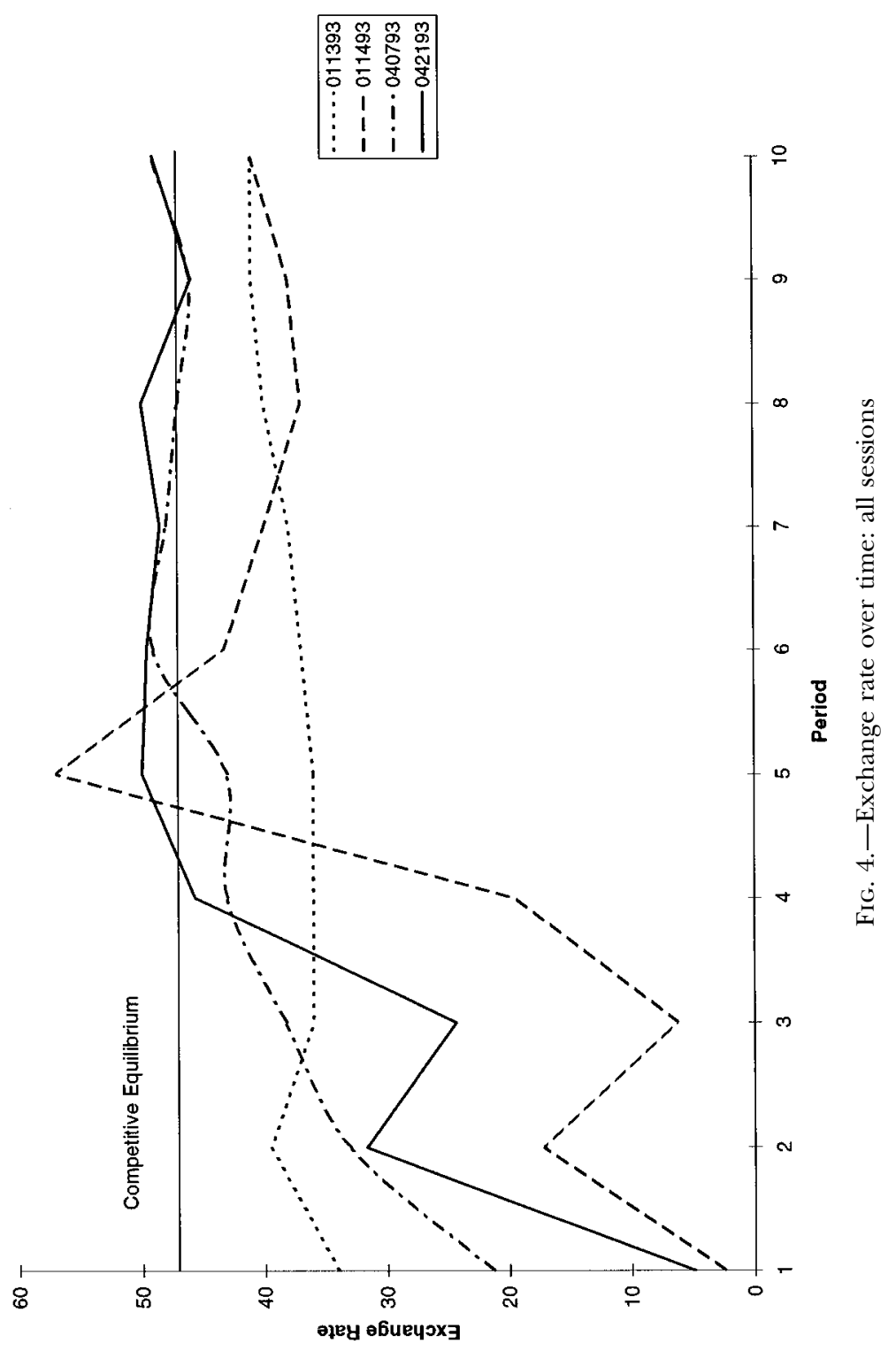




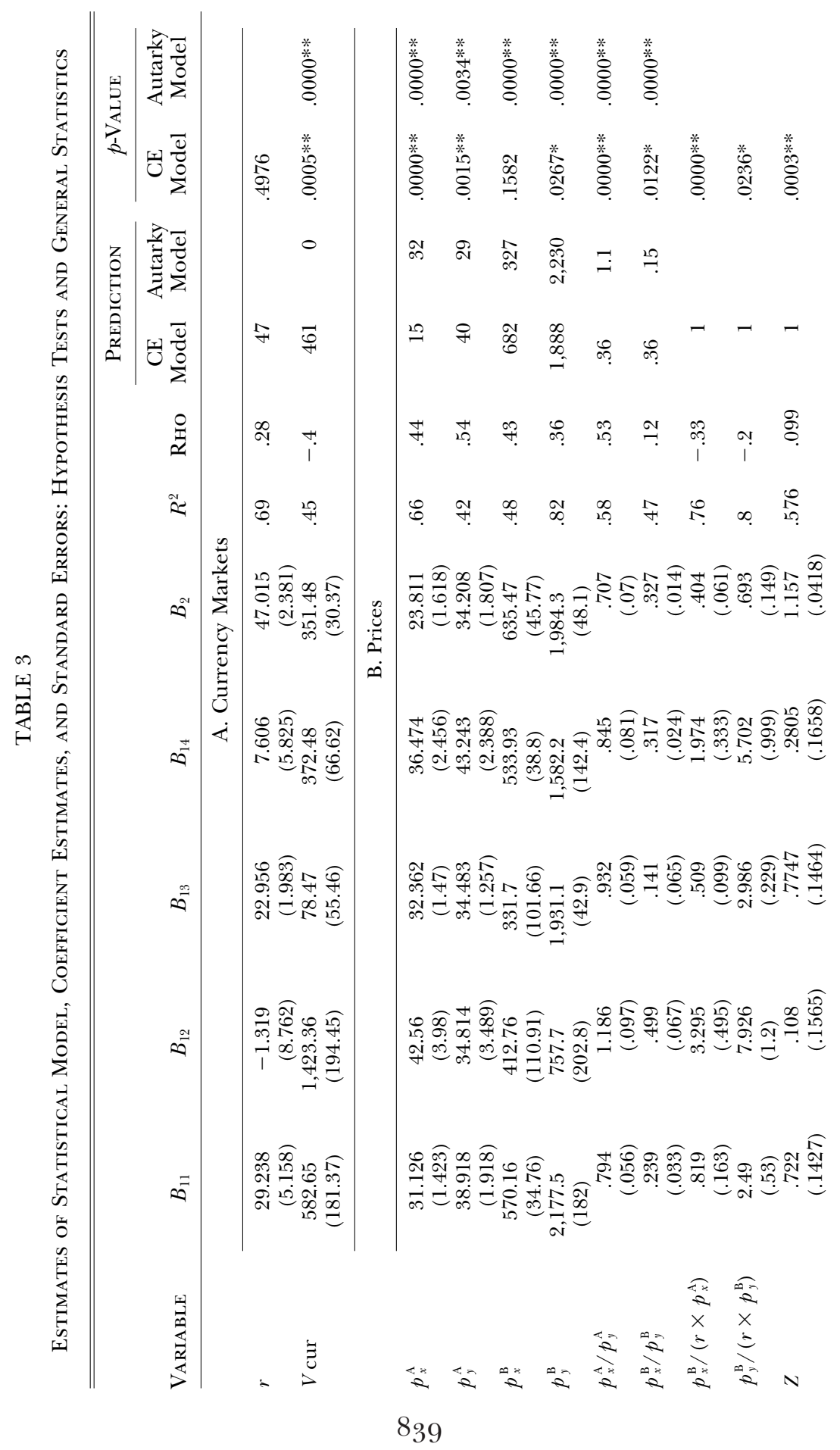




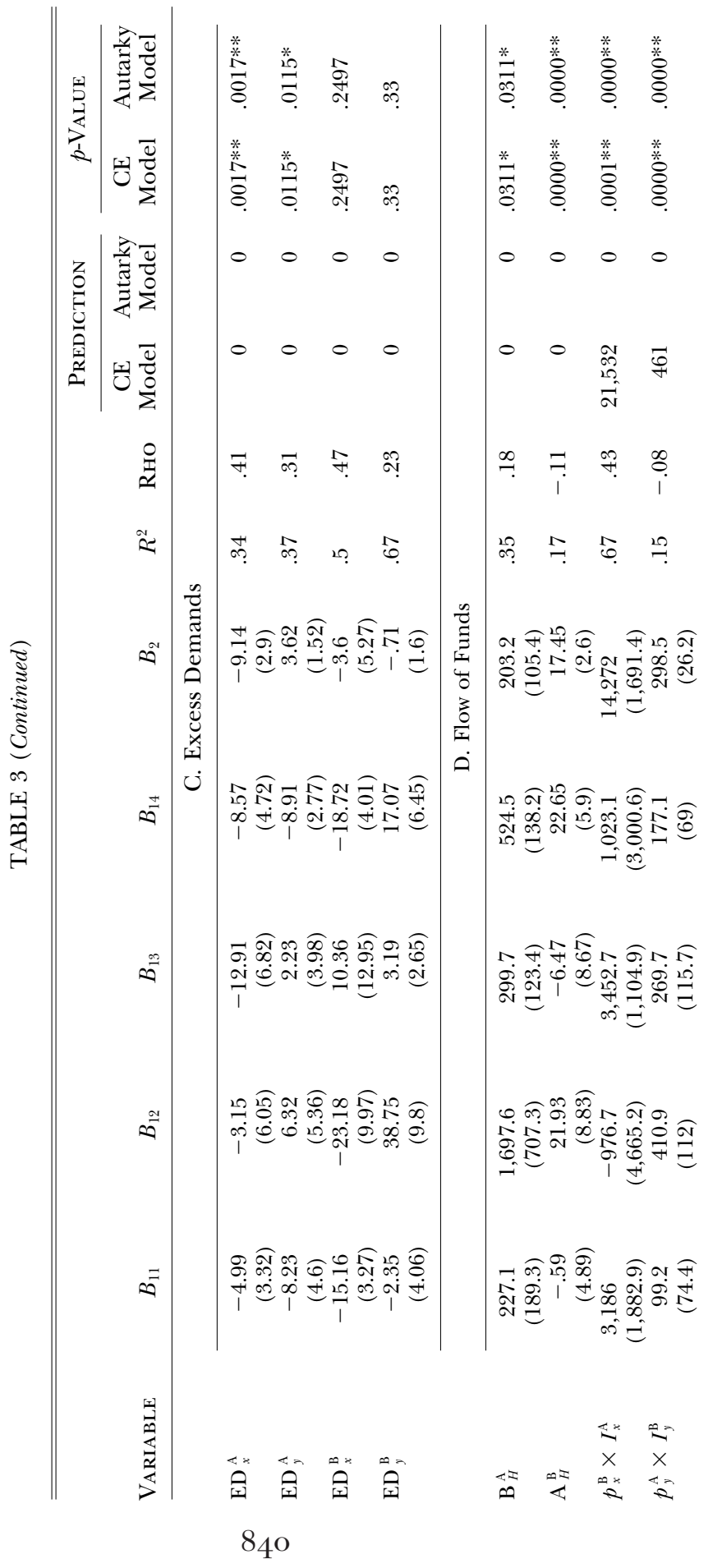




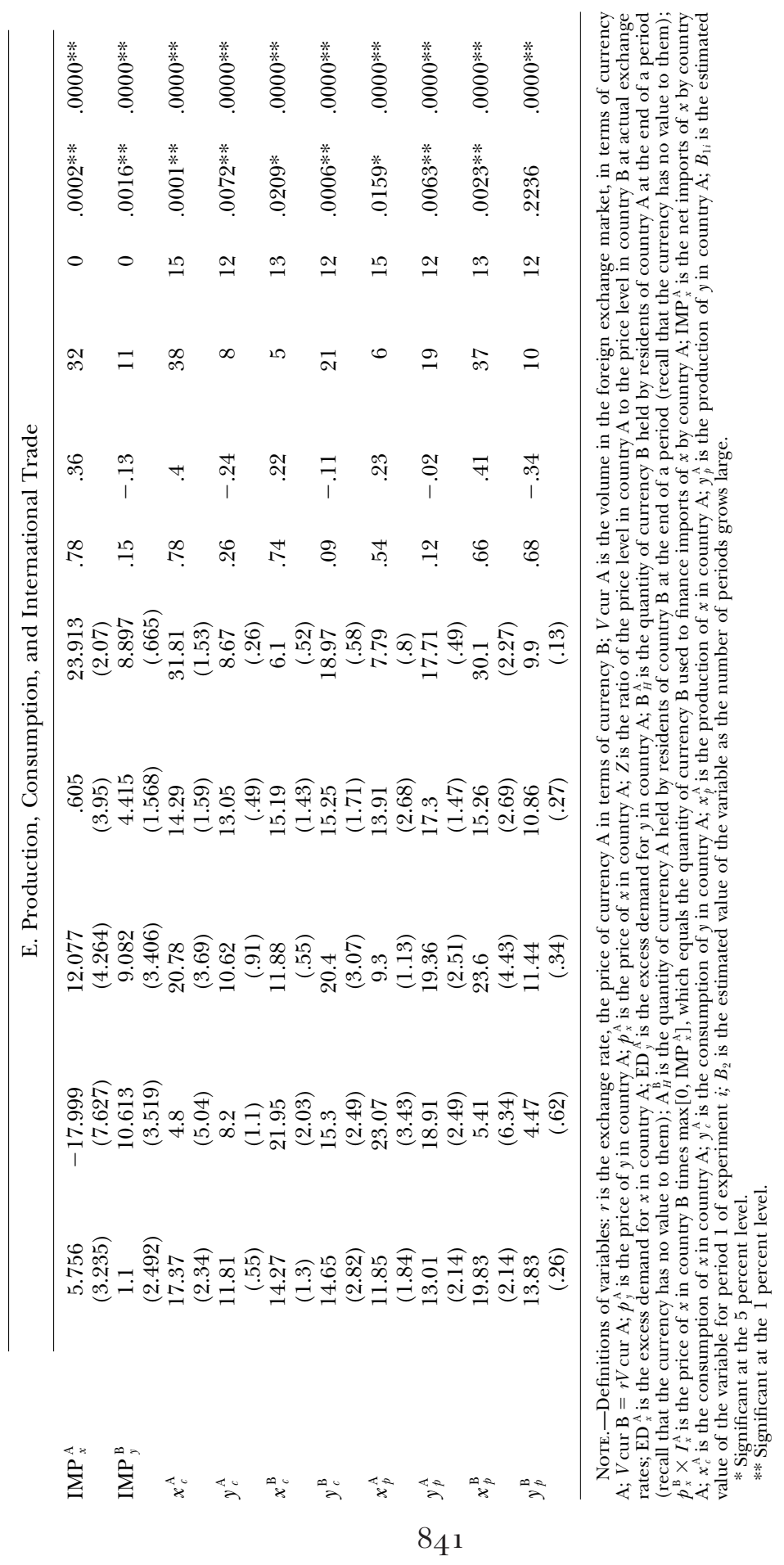


rected for heteroskedasticity using White's (1980) covariance matrix estimator. ${ }^{4}$ The variables analyzed for prices and exchange rates equal the average transaction price during a market period, the unit of observation.

The analysis begins with the most central variables, the exchange rate and the volume of currency exchanged. If the response of these variables to the underlying economic conditions is not as predicted by theory, then the magnitudes of all other variables would be affected relative to theory. The first result is that the exchange rates are at a level anticipated by the competitive model. The second result is that the volume of exchange falls short of the competitive quantity.

Result 1. Exchange rates converge strongly to the competitive prediction.

Support. Refer to the row labeled $r$ in panel A of table 3. The competitive equilibrium exchange rate is 47 . The estimate of $B_{2}$ for $r$, the exchange rate variable, is 47.015 with a standard error of 2.381, as shown in the first row of the table. The hypothesis that the exchange rates are strongly converging to the predictions of the competitive equilibrium model cannot be rejected. Q.E.D.

The volume of exchange for country $B$ is shown in figure 5 . Since the volume of currency in country A is related to the volume of currency in country $\mathrm{B}$ by the exchange rate, only one country is shown. Panel A of table 3 has statistics for country A, whereas the figure has data for country B. For the most part, the figure shows that the competitive model is rejected because of insufficient trade, especially in one of the experiments (experiment 040793). The same conclusion is evident from the table.

Result 2. The volume of exchange in the international market falls short of the competitive equilibrium volume. In only one of the experiments is the volume partially converging to the competitive equilibrium. The autarky model can be rejected.

Support. The estimates from the model are in panel A of table 3, listed as the variable $V$ cur. The estimated asymptote of the volume, $B_{2}$, is 351 compared with the competitive equilibrium volume, which should be at least 461 . It could be more than 461 without being inconsistent with the model because of the possible existence of speculation. The hypothesis that the asymptotic value of the actual volume equals the theoretical value can be rejected. In addition, the

\footnotetext{
${ }^{4}$ The results are not substantially different without the correction for heteroskedasticity. Every coefficient $B_{2}$ that is significantly different at the 5 percent level from the competitive equilibrium or from autarky remains so if the correction is not performed. Likewise, every $B_{2}$ coefficient that is not significantly different from the predictions of one of the models at the 5 percent level with the correction is not significantly different from the model's prediction without the correction.
} 


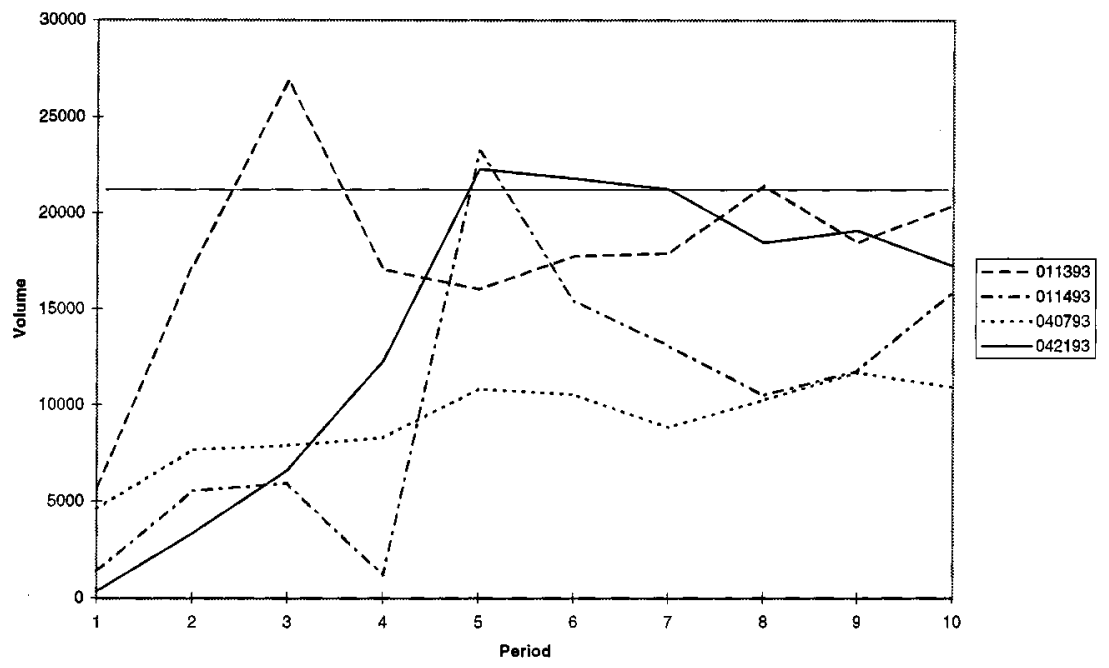

FIG. 5.-Volume in the currency B market over time: all sessions

$B_{1 j}$ terms for at least three experiments are closer to the competitive equilibrium than the asymptote. Since the $B_{1 j}$ terms are the measures of the beginning of the adjustment process, partial convergence is not observed. Q.E.D.

Though the volume of currency $\mathrm{A}$ is not converging toward the competitive equilibrium quantity, the amount of currency B traded increases from very low levels at the beginning of each session toward the competitive equilibrium quantity of 21,532 over the course of the session. This tendency is apparent in figure 5 . The convergence of the volume of currency $\mathrm{B}$, but not currency $\mathrm{A}$, is associated with an increase in $r$, the exchange rate, over the course of each session.

Result 2 serves as a signal that these systems are not exactly on track as described by the competitive equilibrium model. Since the volume is not accurate, the simultaneous nature of the model's equation system suggests that inaccuracies are likely to exist elsewhere. The following results constitute an attempt to isolate the errors and find the fundamental causes. The prices that exist in each country are the obvious places to begin. They are addressed by the following result.

Result 3. Price patterns have the following properties: (i) Prices within countries partially converge to the competitive equilibrium predictions. (ii) Relative prices of $x$ and $y$ are converging in the partial sense toward the competitive equilibrium prediction in both countries. (iii) The competitive equilibrium is a better predictor than autarky is. 
Support. Part i: Panel B of table 3 contains the estimates of the $B_{1 j}$ term for the prices of two countries, two commodities, and four experiments. It contains the estimate of the $B_{2}$ terms for each of the four prices (two countries and two commodities, $p_{x}^{\mathrm{A}}, p_{y}^{\mathrm{A}}, p_{x}^{\mathrm{B}}$, and $\left.p_{y}^{\mathrm{B}}\right)$. Three of the four $B_{2}$ terms, which are measures of the price asymptotes, are significantly different from the prediction of the competitive model, and all four are different from that of autarky. In all but five cases (four instances of $p_{y}^{\mathrm{A}}$ and one instance of $p_{y}^{\mathrm{B}}$ ) of the 16 possibilities, the data are further from the competitive equilibrium at the start of the experiment than at the end. Part ii: Panel $\mathrm{B}$ of table 3 contains the test for the variables $p_{x}^{\mathrm{A}} / p_{y}^{\mathrm{A}}$ and $p_{x}^{\mathrm{B}} / p_{y}^{\mathrm{B}}$. As can be seen, the hypothesis that $B_{2}$ is the ratio that is predicted by the competitive equilibrium can be rejected in both cases (two countries and two price ratios). The ratios seem close to 0.7 and 0.33 compared to the equilibrium predictions of 0.36 , and the differences are statistically significant. The partial convergence is clearly present since, in all eight possible cases, the data at the beginning of the experiment are further from the competitive equilibrium than are the pooled data at the end. Part iii: In both cases the $B_{2}$ estimate is closer to the competitive equilibrium than it is to the autarky predictions. Q.E.D.

It is interesting to note that while the absolute prices are not at the competitive equilibrium, the movements are in that direction. Furthermore, the price ratios in both countries are not at the competitive levels, but the movement is in that direction. Thus the relative scarcities in a country are being reflected by prices even though the absolute levels of prices are off.

The previous result examined the data from the point of view of prices within a country. The next result views the data from the perspective of relative prices across countries and factors in the exchange rate. It indicates that the nature of the responses of the variables to the underlying economic conditions might differ according to the commodity.

Result 4. The law of one price, as defined by equations (5) and (6), receives some support in the market for $y$ but is rejected in the market for $x$. Partial convergence is not present in the $x$ market but is present in the $y$ market.

Support. The test statistics are in panel B of table 3 for the variables $p_{x}^{\mathrm{B}} /\left(r \times p_{x}^{\mathrm{A}}\right)$ and $p_{y}^{\mathrm{B}} /\left(r \times p_{y}^{\mathrm{A}}\right)$. The hypothesis that the equation is satisfied in the $y$ market can be rejected at the .025 level. The coefficient $B_{2}$ is 0.69 , as opposed to the 1.0 predicted by the competitive model. Partial convergence is also present in every experiment. In the $x$ market the coefficient $B_{2}$ is 0.4 , as opposed to 1 . As measured 
by the variable $B_{1 i}$, in the $x$ market, two of the experiments are closer at the end than at the beginning.

The next result extends the analysis to a version of PPP theory. In order to cast the competitive model in the terms in which it is ordinarily applied, price indices are developed and used to reformulate LOP as PPP. Of course, this theory is sensitive to the choice of indices. The result is stated next.

Result 5. Purchasing power parity is not supported statistically in the data.

Support. Price indices were constructed using actual volume as weights. Consider the estimation of the following variable $Z$, where

$$
Z=r\left[\frac{p_{x}^{\mathrm{A}}\left(x_{c}^{\mathrm{A}}+x_{c}^{\mathrm{B}}\right)+p_{y}^{\mathrm{A}}\left(y_{c}^{\mathrm{A}}+y_{c}^{\mathrm{B}}\right)}{p_{x}^{\mathrm{B}}\left(x_{c}^{\mathrm{A}}+x_{c}^{\mathrm{B}}\right)+p_{y}^{\mathrm{B}}\left(y_{c}^{\mathrm{A}}+y_{c}^{\mathrm{B}}\right)}\right] .
$$

The terms $\left[p_{x}^{\mathrm{A}}\left(x_{c}^{\mathrm{A}}+x_{c}^{\mathrm{B}}\right)+p_{y}^{\mathrm{A}}\left(y_{c}^{\mathrm{A}}+y_{c}^{\mathrm{B}}\right)\right]$ and $\left[p_{x}^{\mathrm{B}}\left(x_{c}^{\mathrm{A}}+x_{c}^{\mathrm{B}}\right)+\right.$ $\left.p_{y}^{\mathrm{B}}\left(y_{c}^{\mathrm{A}}+y_{c}^{\mathrm{B}}\right)\right]$ are price indices in countries $\mathrm{A}$ and $\mathrm{B}$, respectively. The prices of the two commodities $x$ and $y$ are weighted by the commodities' shares in the world consumption bundle. Under PPP, the exchange rate equalizes purchasing power in the two countries so that $Z=1$. The estimates are given in panel $\mathrm{B}$ of table 3 in the row labeled $Z$.

As can be seen in the table, the estimated asymptotic value of $Z$, as measured by the variable $B_{2}$, is 1.157 , and it is significantly different from one at the $p<.005$ level. Thus, since the estimated asymptote is about 15 percent off, the PPP model fails. Q.E.D.

Notice that PPP does not fail because of an inappropriate construction of price indices. The theory fails because the underlying and motivating LOP fails. Thus results 5 and 6 together demonstrate that a phenomenon found in the field data, the failure of PPP, is also found in the experimental economies.

The previous three results suggest that inaccuracies of the competitive model reside in both intercountry and intracountry comparisons. The next result is an attempt to focus more clearly on the behavior of the localities in which the price formation process takes place. Equations (1)-(4) are local market demand and supply equations. They say that, in each country and for each commodity, the local prices are set by the local conditions of demand and supply, together with the imports and exports. They are statements about the reaction of domestic economies to the underlying economic forces. The question posed is whether or not excess demand or excess supply, as defined by the actual parameters of the experiment and by the observed prices, exists in the local economies. Have the 
prices adjusted in the domestic economies, or are they adjusting to satisfy the partial equilibrium condition that demand equals supply? The result suggests that the two countries are adjusting much differently.

Result 6. Domestic excess demand for good $x$ is not converging to zero in country A, but for $y$ in country A, it is converging to zero in the partial sense. Domestic excess demand is converging strongly to zero in country B, for $y$ and for $x$.

Support. Excess demand is defined by actual experimental parameters. Prices are average prices in a period. The estimated coefficients in panel $\mathrm{C}$ of table 3 provide the support. In the table, excess demand for $m$ in country $J$ is denoted by $\mathrm{ED}_{m}^{J}$. In country A there is an excess supply of $x$ at the asymptote $B_{2}$, of the adjustment path of 9.1 units. This is significantly different from zero. Furthermore, the asymptote is further from the equilibrium than the starting point in three of the four experiments. Similarly, there is a significant excess demand (3.6 units) for $y$ in country A. However, the market is converging in the partial sense to an excess demand of zero in three of the four experiments. In country B the excess demand for both $x$ and $y$ is converging to zero in the strong sense. Q.E.D.

Result 6 indicates that the law of supply and demand is operating at the local levels, but an inexplicable asymmetry exists between the countries. The question to pose is whether there might exist a deeper problem as a result of the way the law is formulated at the international level to determine the exchange rate. The next result is fundamental. It says that the flow of funds theory is operating to determine the rate of exchange.

Two different types of models can be used to assess the flow of funds theory of exchange rate determination. The first rests on the fact that the international financial flows must satisfy the following accounting identity:

$$
p_{x}^{\mathrm{B}} \times I_{x}^{\mathrm{A}}+p_{y}^{\mathrm{B}} \times I_{y}^{\mathrm{A}}+\mathrm{B}_{H}^{\mathrm{A}}=r\left(p_{x}^{\mathrm{A}} \times I_{x}^{\mathrm{B}}+p_{y}^{\mathrm{A}} \times I_{y}^{\mathrm{B}}+\mathrm{A}_{H}^{\mathrm{B}}\right),
$$

where $J_{H}^{K}$ is the quantity of currency $J$ held at the end of a market period by residents of country $K$, and $I_{m}^{J}=\max \left[0, \operatorname{IMP}_{x}^{J}\right]$, where $\mathrm{IMP}_{m}^{J}$ is the net imports of $m$ by country $J$. The left side of the equation is equal to the total amount of currency B purchased by residents of country A; the right side equals the total amount of currency A purchased by residents of country $\mathrm{B}$, multiplied by the exchange rate, which is the price of currency $\mathrm{A}$ in terms of currency $\mathrm{B}$. The equation does not include purchases and subsequent resale of currency, which is presumably due to speculation. Thus each side of the equation represents currency demanded and supplied for transaction purposes, plus wasted foreign exchange. In terms of the no- 
tation introduced above, $\mathrm{B}_{H}^{\mathrm{A}}$ and $\mathrm{A}_{H}^{\mathrm{B}}$ are the quantities of foreign exchange that are "wasted" in each of the countries A and B, respectively.

The competitive model predicts that

$$
\begin{gathered}
p_{x}^{\mathrm{B}} \times I_{x}^{\mathrm{A}}+p_{y}^{\mathrm{B}} \times I_{y}^{\mathrm{A}}+\mathrm{B}_{H}^{\mathrm{A}}=21,532, \\
p_{x}^{\mathrm{A}} \times I_{x}^{\mathrm{B}}+p_{y}^{\mathrm{A}} \times I_{y}^{\mathrm{B}}+\mathrm{A}_{H}^{\mathrm{B}}=461, \\
r=47,
\end{gathered}
$$

and

$$
p_{y}^{\mathrm{B}} \times I_{y}^{\mathrm{A}}=\mathrm{B}_{H}^{\mathrm{A}}=\mathrm{A}_{H}^{\mathrm{B}}=p_{x}^{\mathrm{A}} \times I_{x}^{\mathrm{B}}=0 .
$$

The first approach to flow of funds theory testing rests on interpretations of statistical tests of the last two equations. The data are captured by result 7 .

Result 7. The international flow of funds is moving toward the competitive equilibrium prediction.

Support. The variable $p_{y}^{\mathrm{B}} \times I_{y}^{\mathrm{A}}=0$ in every period of every experiment. The variable $p_{x}^{\mathrm{A}} \times I_{x}^{\mathrm{B}}=0$ in every period of every experiment except for the first three periods of experiment 011493. It can be seen from panel $\mathrm{D}$ of table 3 that the variables $\mathrm{B}_{H}^{\mathrm{A}}$ and $p_{x}^{\mathrm{B}} \times I_{x}^{\mathrm{A}}$ are converging in the partial sense to the competitive predictions in all four experiments, whereas $r$ is converging strongly. The variable $\mathrm{A}_{H}^{\mathrm{B}}$ is converging partially in two of the four experiments and $p_{y}^{\mathrm{A}} \times$ $I_{y}^{\mathrm{B}}$ is converging partially in three of the four experiments. Q.E.D.

Result 7 indicates that the international flow of currency is converging toward the level predicted by the competitive model. It is obviously moving away from the autarky prediction of zero. Thus, even though the volume in the currency market is not moving to the competitive equilibrium prediction in result 2 , the individual components of the demand for and supply of currency, as expressed in equation (9), are moving toward the predicted values. The poor performance of the competitive model in predicting the volume in the currency markets may be due to mistakes and speculation in the early periods of the experimental sessions. Now we consider the second approach, which is more deeply related to the dynamic relationship between $r$ and the international demand for and supply of currencies.

The second approach to testing flow of funds theory is based on a hypothesis about the market. The test rests on the hypothesis that the direction of movement of the exchange rate from period $t-1$ to period $t$ is governed by the market conditions existing in period $t-1$. If there was excess demand for currency A at the average exchange rate in period $t-1$, we would expect $r$ to rise in period 
$t$. This idea is expressed in the following equation:

$$
r_{t}-r_{t-1}=a+b\left(\mathscr{D}_{t-1}^{\mathrm{A}}-\mathscr{Y}_{t-1}^{\mathrm{A}}\right),
$$

where $\mathscr{D}_{t-1}^{\mathrm{A}}$ and $\mathscr{Y}_{t-1}^{\mathrm{A}}$ can be interpreted as the excess demand for and excess supply of, respectively, currency A in period $t-1$. Specifically,

$$
\mathscr{S}_{t-1}^{\mathrm{A}}=\left[D_{x}^{\mathrm{A}}\left(\frac{p_{x}^{\mathrm{B}}}{r}\right)-x_{c}^{\mathrm{A}}\right] \times \frac{p_{x}^{\mathrm{B}}}{r},
$$

where $D_{x}^{\mathrm{A}}(p)$ is the market demand function for $x$ by residents of country A evaluated at price $p$, and $x_{c}^{\mathrm{A}}$ is the total consumption of $x$ by residents of country A. Thus $D_{x}^{\mathrm{A}}-x_{c}^{\mathrm{A}}$ is the additional amount of $x$ that A could profitably import, given the foreign prices of $x$ and its home consumption, which it did not import. When $D_{x}^{\mathrm{A}}-x_{c}^{\mathrm{A}}$ is multiplied by foreign prices and the exchange rate, it yields the amount of home currency that must be spent to import the desired additional amount; thus it is the excess supply of currency A to the international market.

Similarly,

$$
\mathscr{D}_{t-1}^{\mathrm{A}}=\left[D_{y}^{\mathrm{B}}\left(p_{y}^{\mathrm{A}} \times r\right)-y_{c}^{\mathrm{B}}\right] \times p_{y}^{\mathrm{A}},
$$

where $D_{y}^{\mathrm{B}}$ equals the demand for good $y$ by residents of country B, which imports good $y$, measured at the actual country A prices and exchange rate. When consumption of home and foreign production is subtracted from desired consumption, a model of excess import demand is obtained. Multiplication by $p_{y}^{\mathrm{A}}$ yields the amount of currency A needed to make the purchases and thus yields a model of international excess demand for currency A.

The model rests on the hypothesis that $b>0$. This maintains that the exchange rate increases in response to excess demand and decreases in response to excess supply of currency A. Furthermore, the concepts of demand and supply are those that are built from the flow of funds theory of international exchange rate determination. An examination of the data produces the finding contained in result 8 .

Result 8 . The movement of the exchange rate from one market period to the next is influenced by the international demand for and supply of currency as defined by flow of funds theory as captured in equation (14).

Support. The estimated coefficients and standard errors of equation (14) are given in table 4 . Clearly $b>0$, since the hypothesis that $b=0$ can be rejected at the $p<.01$ level. A positive value for $b$ means that excess demand for currency leads to a higher exchange 
TABLE 4

Estimates of the Dynamic Model of Exchange Rate Adjustment

\begin{tabular}{lccc}
\hline \hline Variable & Coefficient & Standard Error & $t$-Statistic \\
\hline$a$ & 1.885 & 1.470 & 1.282 \\
$b$ & .000753 & .000307 & 2.453 \\
\hline
\end{tabular}

NoTE. $-R^{2}=.17 ;$ Durbin-Watson $=2.32$.

rate in the next period. Although the coefficient is small, it indicates the change in $r$ for each unit of excess demand of A, the magnitude of which was typically in the hundreds. The constant term is positive but not significantly different from zero, suggesting a weak upward trend over time, even when excess demand for and supply of currency are taken into account. Thus the dynamic pattern of movement follows the hypothesized property: an excess demand for a currency in the flow of funds sense in period $t$ means an increase in the exchange rate in period $t+1$. Q.E.D.

The issue of dynamics is pursued further by a conjecture about the direction of convergence. It is very clear from panel A of table 3 and figure 4 that the exchange rate is converging from below. Since this is the first experimental study of an economy with multiple currencies, any possible conjecture about the causes of the pattern of convergence is speculative, but it is tempting to draw an analogy with other market experiments. In single-market double auctions it has been observed that the direction of convergence of prices over time can be explained by the relative rents obtained by consumers and producers in the competitive equilibrium (Smith and Williams 1982). Rents tend to be divided more equally between both sides of the market at the beginning of the experiment than in the competitive equilibrium. The conjecture below generalizes this idea to the level of international economies.

Define the equal system surplus price adjustment path to be a movement of the exchange rate such that (i) the exchange rate begins at a level such that total gains from international trade are divided equally and (ii) the exchange rate is converging to the competitive equilibrium level. The concept of relative surplus of buyers and sellers in the currency market can be expressed as the relative gains in surplus of the two countries from international trade. For each country, the gain can be expressed as the sum of the profits (in terms of currency A) of the residents of the country in the competitive equilibrium minus the sum of the residents' profits in autarky. Explicitly the concept is the following.

Let $\mathrm{CE}$ equal the competitive equilibrium allocation and prices, 
AUT the autarky equilibrium allocation and prices, and $\Pi^{K}(z, \mathbf{p})$ the consumers' surplus plus producers' surplus of country $K$ in allocation $z$ and at price vector $\mathbf{p}$ measured in terms of currency $K$. These magnitudes will be precisely defined when they are used in the discussion below.

The equal system surplus price adjustment path is an exchange rate path that begins with an exchange rate $r$ that solves the equation

$$
\Pi^{\mathrm{A}}(\mathrm{CE})-\Pi^{\mathrm{A}}(\mathrm{AUT})=\left[\Pi^{\mathrm{B}}(\mathrm{CE})-\Pi^{\mathrm{B}}(\mathrm{AUT})\right] \frac{1}{r} .
$$

The numbers for the experimental parameters are $\left[\Pi^{A}(\mathrm{CE})\right.$; $\left.\Pi^{\mathrm{A}}(\mathrm{AUT})\right]=[949 ; 581]$ and $\left[\Pi^{\mathrm{B}}(\mathrm{CE}) ; \Pi^{\mathrm{B}}(\mathrm{AUT})\right]=[27,272 ;$ 19,697]..$^{5}$ The equation thus becomes $369=7,575 / r$. The $r$ that equates the surpluses is thus 20.53. According to this model, one would expect the exchange rate to converge from below beginning near 20, moving upward and seeking a limit at the competitive equilibrium of 47 .

Conjecture 1. The direction of convergence of the exchange rate over time is determined by the equal system surplus price adjustment path.

Support. A more equal division of the surplus than in the competitive equilibrium would imply that the exchange rate at the beginning of the experiment should tend to favor country B more than the

$$
\begin{aligned}
& { }^{5} \text { The calculations of the surpluses are made possible because of the separability } \\
& \text { built into the experimental parameters. Inverse demand functions are well defined. } \\
& \text { Let the inverse of a function be indicated by lowercase letters. That is, the demand } \\
& \text { function } D_{x}^{\mathrm{A}}(\cdot) \text { has an inverse function designated by the notation } d_{x}^{\mathrm{A}}(\cdot) \text {. Thus, for } \\
& \text { country A the difference between consumer plus producer surplus evaluated at the } \\
& \text { competitive equilibrium and the consumer plus producer surplus evaluated at the } \\
& \text { autarky equilibrium is } \\
& \qquad \int_{0}^{x_{c}^{\mathrm{A}, \mathrm{CE}}}\left[d_{x}^{\mathrm{A}}(X)-p_{x}^{\mathrm{A}, \mathrm{CE}}\right] d X+\int_{0}^{y_{c}^{\mathrm{A}, \mathrm{CE}}}\left[d_{x}^{\mathrm{A}}(Y)-p_{y}^{\mathrm{A}, \mathrm{CE}}\right] d Y \\
& \qquad-\int_{0}^{x_{p}^{\mathrm{A}, \mathrm{CE}}}\left[p_{x}^{\mathrm{A}, \mathrm{CE}}-s_{x}^{\mathrm{A}}(X)\right] d X+\int_{0}^{y_{p}^{\mathrm{A}, \mathrm{CE}}}\left[p_{y}^{\mathrm{A}, \mathrm{CE}}-s_{y}^{\mathrm{A}}(Y)\right] d Y \\
& \qquad-\int_{0}^{x_{c}^{\mathrm{A}, \mathrm{AUT}}}\left[d_{x}^{\mathrm{A}}(X)-p_{x}^{\mathrm{A}, \mathrm{AUT}}\right] d X-\int_{0}^{y_{c}^{\mathrm{A}, \mathrm{AUT}}}\left[d_{y}^{\mathrm{A}}(Y)-p_{y}^{\mathrm{A}, \mathrm{AUT}}\right] d Y \\
& -\int_{0}^{x_{p}^{\mathrm{A}, \mathrm{AUT}}}\left[p_{x}^{\mathrm{A}, \mathrm{AUT}}-s_{x}^{\mathrm{A}}(X)\right] d X-\int_{0}^{y_{p}^{\mathrm{A}, \mathrm{AUT}}}\left[p_{y}^{\mathrm{A}, \mathrm{AUT}}-s_{y}^{\mathrm{A}}(Y)\right] d Y,
\end{aligned}
$$

where $x_{c}^{\mathrm{A}, \mathrm{CE}}, x_{p}^{\mathrm{A}, \mathrm{CE}}, y_{c}^{\mathrm{A}, \mathrm{CE}}$, and $y_{p}^{\mathrm{A}, \mathrm{CE}}$ are the quantities of $x$ and $y$ consumed and produced in country A at the competitive equilibrium. The amounts at the autarky equilibrium are indicated with the notation AUT replacing CE. Similarly, the equilibrium prices at the competitive equilibrium and autarky are indicated with the country as a superscript and the commodity as a subscript. A similar calculation can be made for country B. The actual numbers are obtained by substituting the inverse demand functions and supply functions from the formulas used as parameters in the experiment that are found in Sec. II. 
competitive equilibrium exchange rate, indicating that currency $\mathrm{B}$ should have a higher value than in the competitive equilibrium. This implies an exchange rate less than 47 at the beginning of the experiment, with a pattern of convergence toward the competitive level. The equal system surplus price adjustment path begins with an exchange rate of 21 . The estimates of the first-period exchange rates for the four experiments found in panel A of table 3 are 29.238, $-1.319,22.956$, and 7.606 , respectively (an average of about 15). Thus adjustment occurs from below in all experiments. The data support the conjecture. Q.E.D.

The results above suggest that patterns of international finance are similar but not exactly as predicted by the competitive model. For the most part the financial variables are moving in directions that would be suggested by the competitive equilibrium model. Either wasted exchange or speculation occurs at first but decreases over time. The next series of questions inquire about the real sectors of the economies and the underlying trade. Since the financial variables are moving in ways that the competitive model anticipates, it might be expected that the real sectors are responding accordingly also. The next result confirms this. It says that the patterns of trade are consistent with competitive theory.

Result 9. International trade patterns are consistent with the principle of comparative advantage.

Support. The competitive model predicts that country A will import $x$ and country B will import $y$. As shown in panel $\mathrm{E}$ of table 3 , net imports of $x$ by country A, denoted by $\operatorname{IMP}_{x}^{\mathrm{A}}$ in the table, are 23.9 units and net imports of $y$ by country B are 8.9 units. These levels are short of the quantitative predictions of the competitive model of 32 units and 11 units, respectively; however, in all but two of the eight possible cases, the data are moving toward the competitive equilibrium quantities. These patterns are sufficient to support the result. Q.E.D.

Since trade is developing along the lines of comparative advantage and since the financial sectors are not far out of line, both consumption and production patterns should be conforming to the model. Since such conformity need not be the case, except as dictated by the principles of economics, which are under investigation, it is necessary to check. The next two results indicate that both are moving in the directions anticipated.

RESUlt 10. Consumption patterns are moving toward the predictions of the competitive model.

Support. Two countries and two commodities represent four variables to consider. The variables are given as $x_{c}^{\mathrm{A}}, y_{c}^{\mathrm{A}}, x_{c}^{\mathrm{B}}$, and $y_{c}^{\mathrm{B}}$ in panel $\mathrm{E}$ of table 3 . All four of these variables are significantly differ- 
ent from the competitive equilibrium as measured by the $B_{2}$ term. But, in a sense, they are very close. For example, there are 8.67 units of consumption of $y$ in country A (the competitive equilibrium is eight units) and 6.1 units of consumption of $x$ in country B (the competitive equilibrium is five units). The variables are partially converging in all but two of the 16 possible cases (as measured by the $B_{1 i}$ estimates as opposed to the $B_{2}$ estimates).

Result 11. Production patterns are moving toward the predictions of the competitive equilibrium model.

Support. In 14 of the 16 cases (four variables and four experiments) the production levels are partially converging to the competitive equilibrium. See the rows marked $x_{p}^{\mathrm{A}}, y_{p}^{\mathrm{A}}, x_{p}^{\mathrm{B}}$, and $y_{p}^{\mathrm{B}}$ in panel $\mathrm{E}$ of table 3 .

In an earlier work (Noussair et al. 1995), we demonstrated that the patterns of production and trade predicted by the law of comparative advantage are observed in an experimental market. In those markets, members of different countries used the same currency. Results 9, 10, and 11 confirm that when members of each country use their own national currency to trade, the law of comparative advantage still works well.

\section{The LOP and PPP Paradox}

A phenomenon that has been widely observed in the field is also observed in the experimental economies. The equations derived from PPP theory fail to be satisfied in the data. How can that be? The experimental economies are much simpler than the field counterparts. None of the conditions that might be troublesome to the theory in the field is present in the experimental economies. One could surmise that the experimental economies operate under conditions that are very favorable to the theory. Indeed, not only does PPP fail, but also the underlying and more fundamental theory, LOP. Thus the experimental economies demonstrate that PPP and LOP can fail for more fundamental reasons than has been supposed in the literature.

We offer an observation and a conjecture about what the reason for the failure might be. The first is related to the inherent uncertainty in international finance. The second is related to the inherent interdependence in a multicountry and multicurrency economy.

Observation.-When trading in foreign economies, agents take unavoidable risks. All actions and prices must include a risk premium.

Trading in the experimental environment involves risks that are inherent in the trading technology. In the experimental economies, agents must buy foreign exchange before they can trade in the for- 
eign commodity market. Thus agents must commit to buying the currency (which is worthless to them except to buy foreign goods) in the foreign market before they know at what price they will actually trade. This risk is not due to traders' lack of knowledge about the value of a system variable, but rather to uncertainty about whether the markets will adjust to their equilibrium values and exactly how and when this takes place. Thus there is not a way for them to hedge this risk, although it would presumably be small if the time lags were short. Nevertheless, previous experience in similar experiments leads us to believe that agents must be compensated for taking the extra risk. This could explain why even though the exchange rate market equilibrates, LOP and PPP fail.

The conjecture is a type of coordination hypothesis. It results from the nature of simultaneously interacting markets.

Conjecture 2. The law of one price fails because of the asymmetric speed of adjustments of the price discovery process of local markets.

That fact that markets converge at different speeds is well known to those that study experimental markets. This fact becomes important to the issue of LOP in international finance. In order for LOP (and to a lesser extent PPP) to be satisfied as an equilibrium condition, all markets have to be in equilibrium simultaneously. In fact, what happens in the experimental economies is that markets converge at different speeds, and within the time frames that were possible to observe, the simultaneous equilibration of all markets never occurred (see result 6 ). This phenomenon leads to the failure of LOP even when the exchange rate has converged to the level predicted by the competitive equilibrium model. Thus, if the same principles of economics operate in the field as are operating in the experimental markets, LOP and PPP may fail because there are multiple markets that are spatially separated, and the price discovery process in the different markets operates at different speeds. ${ }^{6}$

We are unaware of any coherent, general model that might be applied to capture all the complex adjustments that occur in the experimental economies and will help us make the point rigorously. However, the observation about risk premiums and conjecture 2 operate together with other results to form an impression of how the LOP failure occurs even under favorable circumstances. From conjecture 1 comes the proposition that the asymmetric gains from in-

${ }^{6}$ There are suggestions in the literature that LOP and PPP fail because trading takes time (Benninga and Protopapadakis 1988; Goodwin, Grennes, and Wohlgenant 1990). While we see no inconsistency between our observations and their models, the role of time in their models is difficult to make operational in the experimental economies. 
ternational trade influence the exchange rate to converge from below. Similarly, international trade, because of the inherent risks, starts around the cautious, autarky level of zero and then moves upward. So if international trade approaches the competitive equilibrium levels, it will approach from below. That property is observed in the experimental markets.

Overall, the system is observed to move in the direction of the competitive equilibrium. Early in the experiment, currency A is selling for below its competitive equilibrium level and currency B sells for more than the competitive equilibrium. Thus, in this position of disequilibrium, it is expensive for country A to import $x$ as it is supposed to, and with the lack of supply and competition from international sources, the prices of $x$ in country A are high, relative to the competitive equilibrium. Similarly, in country B there is little international demand for $x$ because of the low exchange rate, so the price is low relative to the competitive equilibrium. In both cases the prices of $x$ respond according to this picture, with the $x$ prices starting above the equilibrium prices in country $\mathrm{A}$ and converging downward and the $x$ prices in country B starting below the competitive equilibrium and converging upward. The fact of risk buttresses these tendencies by decreasing the imports of $x$ and thereby keeping the prices of $x$ high in country A and low in country B.

The influence of these pressures on the prices of $y$ is different. In country A the low exchange rate should place upward pressure on price because of the international demand, but this pressure is offset by the risk of international transactions. The excess demand at the disequilibrium exchange rate is not as strong as it would be if there were no risks, and thus the potential upward pressure on price is muted. Similarly in country $\mathrm{B}$, the low exchange rate should be accompanied by substantial imports of $y$ with an accompanying downward pressure on price. But the risk of international finance mutes the importation of $y$ and thereby decreases the excess supply that would force prices down. These "cross pressures" result in ambiguous price movements of $y$ in both countries.

\section{Conclusions}

The autarky model can be solidly rejected by these experiments. It is not the case that the hazards of the foreign exchange markets are such that international trade stops or takes place at very low levels only. On the other hand, the competitive model is not perfect. In most instances the outcome variables are converging to the competitive prediction in the partial sense, but the model fails to predict the exact levels of activity in many instances, even when the asymptotic 
tendencies are incorporated. Financial hazards of participation in international trade do exist and can appear in the form of "wasted" exchange. However, the equilibrating tendencies of the system serve to reduce the uncertainty and facilitate trade.

Generally speaking, the exchange rate seeks a level that is near that predicted by the competitive model. Although the volume in the currency market is less than the competitive level, the individual components of currency flows seem to be moving toward the model's predictions. The exchange rate movements from one period to the next respond to the excess demand and supply conditions prevailing in the currency market. Over the course of the experiment, the exchange rate moves in accordance with the equal system surplus adjustment path. The low volume in the foreign exchange market suggests that the full gains from trade are not being realized, and, indeed, international trade is below competitive levels. This relatively low level of international trade may be associated with the relative prices lying between the competitive and autarky predictions in both countries. Country A seems to be more problematic, with the price of $x$ persistently much higher than the competitive equilibrium level.

The low level of international trade observed in the experiments may be due to the systemic risk resulting from the cash-in-advance constraint. The risk of possible losses from holding foreign currency when the market period ends, or having to sell it at a loss, requires the would-be importer to be compensated for engaging in international trade. Importing is worth it only for those units of $x$ and $y$ for which the gains from international trade are great and is not worth it for marginal units, which are therefore not imported. Thus the cash-in-advance constraint functions much like an excise tax or a tariff on international transactions, reducing the amount of international trade of $x$ and $y$ to below the competitive equilibrium level.

In general, prices within countries do not seem to be adjusting rapidly to local demand and supply conditions, although there is evidence of slow convergence to local market clearing. The adjustment is not taking place at all for market $x$ in country A.

A perplexing phenomenon that has been observed in the field appears in the experimental markets. The law of one price and purchasing power parity fail. This failure of LOP and PPP can be traced to the differing speeds at which markets adjust in the different countries. Thus, in the economies studied here, the mystery of the failures resides in the nature of price dynamics in local economies. The problems do not reside with the complete apparatus of the competitive model. In these economies, PPP cannot fail because of problems with price indexes since accurate indexes were constructed. In addi- 
tion, there are no trade barriers, nontraded goods, or transportation costs. Thus we are able to conclude that the phenomena can have another cause besides the variables that have been the focus of modern investigations. Violations of LOP and PPP arise naturally as disequilibrium phenomena, even in simple laboratory international economies.

Despite the behavior of local and international price ratios, which show departure from the competitive equilibrium levels, the real sectors of the economies are moving in the direction of the competitive equilibrium. Patterns of international trade are consistent with the law of comparative advantage. Local production and consumption levels are converging to the competitive equilibrium as well.

The competitive model is not perfect, in any sense, but the principles on which the general theory is based lead to a model that predicts the general movement of economic activity in a very complex and interdependent setting. When people discuss vague concepts of "economic forces," these data suggest that the formalization of the concepts with the competitive equilibrium model can be very useful. The forces are increasing the international trade between the two countries, with the result that the magnitudes of most outcome variables, especially net exports, production, consumption, and the exchange rate, move slowly toward the competitive equilibrium.

\section{Appendix}

\section{Instructions and Forms}

\section{General Instructions}

This is an experiment in the economics of market decision making. The instructions are simple and if you follow them carefully and make good decisions, you might earn a considerable amount of money which will be paid to you in cash.

In the experiment we are going to conduct a market in which some of you will be buyers and some of you will be sellers in a sequence of trading periods. Find a sheet labelled Buyer or Seller, which describes the value to you of any decisions you might make. You are not to reveal the information on this sheet to anyone. It is your own private information.

In the experiment there are two goods and two locations, which you could think of as separate countries. The goods are called $\mathrm{X}$ and $\mathrm{Y}$ and the locations are called A and $\mathrm{B}$. In location $\mathrm{A}$, there is a market for $\mathrm{X}$ and $\mathrm{a}$ market for $\mathrm{Y}$. Also, in location $\mathrm{B}$, there is a market for $\mathrm{X}$ and a market for Y. As will be explained later, the locations will be on different screens on the computer.

Each location has its own special currency. All transactions in location A will take place in currency A and all transactions in location B will take 
place in currency B. Each unit of currency A is worth guilders to you and each unit of currency B is worth guilders to you.

\section{Specific Instructions to Sellers}

During each market period you are free to sell to any buyer or buyers as many units of $\mathrm{X}$ and $\mathrm{Y}$ as you might want. The first unit of $\mathrm{X}$ that you sell in a trading period, you obtain at a cost of the amount listed on the sheet in row (1) in the section of the sheet entitled Cost Schedule for X, in the column labelled unit cost. The second unit of $\mathrm{X}$ that you sell during the same trading period you obtain at a cost of the amount listed in row (2) in the column marked unit cost, etc. The profits from each sale, which are yours to keep, are computed by taking the difference between price at which you sold the unit and the cost of the unit. That is:

$$
\text { Your Earnings }=\text { Sale Price of Unit }- \text { Cost of Unit }
$$

Suppose, for example, that you sell two units of $\mathrm{X}$ and that the cost for the first unit of $\mathrm{X}$ is 140 and for the second unit is 160. If you sell the first unit at 200 and the second at 190, your earnings are

$$
\begin{aligned}
\text { Earnings from First } & =200-140=60 \\
\text { Earnings from Second } & =190-160=30 \\
\text { Total Earnings } & =60+30=90
\end{aligned}
$$

The end of period summary will help you record your profits. On row $\mathrm{A}$, record the total cost of $\mathrm{X}$ that you sold during the period. The $\mathrm{X}$ which you sold during the period is equal to your inventory of $\mathrm{X}$ at the beginning of the market period minus your inventory at the end of the market period. This total can be found in the row of the section labelled Cost Schedule for $\mathrm{X}$ corresponding to the amount of $\mathrm{X}$ you sold during the period in the last column, which is entitled total cost. For example, if you sold two units during the market period, the total cost can be found in row (2). Similarly, on row $\mathrm{B}$, record the total cost of $\mathrm{Y}$ that you sold during the period.

On rows $(\mathrm{C})$ and $(\mathrm{D})$ record your beginning of period and end of period inventory of the currency which has value to you. On row (E), enter an amount equal to the amount in row (D) minus the amount in row $(\mathrm{C})$. (E) indicates your net change in cash for the market period. On row $(\mathrm{F})$ record your total profit for the period. The total profit equals the total cash obtained from sales of $\mathrm{X}$ and $\mathrm{Y}$ minus the cost of the $\mathrm{X}$ and $\mathrm{Y}$ sold. It also equals the amount in row (E) minus the amount in row (A) minus the amount in row (B). Subsequent periods should be recorded similarly.

\section{Specific Instructions to Buyers}

During each market period, you are free to purchase from any seller or sellers as many units of $\mathrm{X}$ and $\mathrm{Y}$ as you might want. For the first unit of $\mathrm{X}$ that you buy in a trading period, you will receive the amount listed in row (1) in the section of the page entitled redemption value schedule for $\mathrm{X}$ in 
the column marked unit value. If you buy a second unit during the trading period, you will receive the additional amount listed in row (2) in the column marked unit redemption value, etc. The profits from each purchase, which are yours to keep, are computed by taking the difference between the redemption value and the purchase price of the unit bought. That is:

$$
\text { Your Earnings }=\text { Redemption Value }- \text { Purchase Price }
$$

Suppose, for example, that you buy two units and that your redemption value for the first unit is 200 and for the second unit is 180. If you pay 150 for the first unit and 160 for the second unit, your earnings are:

$$
\begin{aligned}
\text { Earnings from First } & =200-150=50 \\
\text { Earnings from Second } & =180-160=20 \\
\text { Total Earnings } & =50+20=70
\end{aligned}
$$

The end of period summary will help you record your profits. In row (A) enter the total value of $\mathrm{X}$ consumed. This amount can be found in the column labelled total value in the row corresponding to the total number of $\mathrm{X}$ held in your inventory at the end of the period.

Similarly, record the total value of Y consumed in row (B). On rows (C) and (D) record your beginning of period and end of period inventory of the currency which has value to you. On line (E), enter an amount equal to the amount in row (D) minus the amount in row $(\mathrm{C})$. On line $(\mathrm{F})$ record your total profit for the period, which equals your redemption values for having $\mathrm{X}$ and $\mathrm{Y}$ in your inventory at the end of the market period, minus the cash which you spent to acquire them.

\section{Currency}

The locations are indicated by two computer screens. You can move from screen to screen by using the page up and page down keys. On each screen Cash on Hand is given in the upper right corner. On one screen, which represents location $\mathrm{A}$, the Cash on Hand indicates your inventory of currency $A$. On the other screen, which represents location $B$, the Cash on Hand indicates your inventory of currency B.

While at location A, market 3 allows you to buy and sell currency B. Similarily, while at location B, market 6 allows you to buy and sell currency A.

All participants may transfer units of $\mathrm{X}$ and $\mathrm{Y}$ from one of the locations to the other. Some participants can transfer units of $\mathrm{X}$ and $\mathrm{Y}$ from location $\mathrm{B}$ to location A, but not from location A to location B. The rest of the participants can transfer units of $\mathrm{X}$ and $\mathrm{Y}$ from location $\mathrm{A}$ to location $\mathrm{B}$, but not from B to A. To transfer units, use the F4 key.

\section{Trading Profits}

A possible source of profits is from buying and selling X, Y, currency A, and currency B. Selling increases your cash on hand by the amount of the sale price. Buying reduces your cash on hand by the amount of the pur- 
End of Period Summary: Period

(A) Total Cost of X Sold (in Currency A)

(B) Total Cost of Y Sold (in Currency A)

(C) Beginning of Period Inventory of Currency A

(D) End of Period Inventory of Currency A

(E) Net Change in Currency A

(F) Total Profit for the Period (E) - (A) - (B)

End of Period Summary: Period

(A) Total Value of X in Final Inventory (in Currency B)

(B) Total Value of Y in Final Inventory (in Currency B)

(C) Beginning of Period Inventory of Currency B

(D) End of Period Inventory of Currency B

(E) Net Change in Currency B

(F) Total Profit for the Period (E) + (A) + (B)

chase. Thus, you can either gain or lose money on the purchase and resale of units.

\section{Beginning of Period Inventories}

All sellers begin each period with inventory of X and Y. All buyers begin each period with no X or Y. All participants begin each period with a large inventory of either currency A or currency B. Beginning of period inventories are the same for each market period.

Cost Schedule for X

\begin{tabular}{lcc}
\hline \hline Unit & $\begin{array}{c}\text { Unit Cost } \\
\text { (in Currency B) }\end{array}$ & $\begin{array}{c}\text { Total Cost } \\
\text { (in Currency B) }\end{array}$ \\
\hline$(1)$ & 150 & 150 \\
$(2)$ & 195 & 345 \\
$(3)$ & 240 & 585 \\
$(4)$ & 285 & 870 \\
$(5)$ & 330 & 1,200 \\
$(6)$ & 375 & 1,575 \\
$(7)$ & 420 & 1,995 \\
$(8)$ & 465 & 2,460 \\
$(9)$ & 510 & 2,970 \\
$(10)$ & 555 & 3,525 \\
$(11)$ & 600 & 4,125 \\
$(12)$ & 645 & 4,770 \\
$(13)$ & 690 & 5,460 \\
$(14)$ & 735 & 6,195 \\
$(15)$ & 780 & 6,975 \\
$(16)$ & 825 & 7,800 \\
$(17)$ & 870 & 8,670 \\
$(18)$ & 915 & 9,585 \\
$(19)$ & 960 & 10,545 \\
$(20)$ & 1,005 & 11,550 \\
\hline
\end{tabular}


Redemption Value Schedule for Y

\begin{tabular}{lcc}
\hline \hline Unit & $\begin{array}{c}\text { Unit Value } \\
\text { (in Currency A) }\end{array}$ & $\begin{array}{c}\text { Total Value } \\
\text { (in Currency A) }\end{array}$ \\
\hline$(1)$ & 42 & 42 \\
$(2)$ & 39 & 81 \\
$(3)$ & 36 & 127 \\
$(4)$ & 36 & 163 \\
$(5)$ & 33 & 196 \\
$(6)$ & 30 & 226 \\
$(7)$ & 27 & 253 \\
$(8)$ & 27 & 280 \\
$(9)$ & 24 & 304 \\
$(10)$ & 21 & 325 \\
$(11)$ & 18 & 343 \\
$(12)$ & 18 & 361 \\
$(13)$ & 15 & 376 \\
$(14)$ & 12 & 388 \\
$(15)$ & 9 & 397 \\
$(16)$ & 9 & 406 \\
$(17)$ & 6 & 412 \\
$(18)$ & 3 & 415 \\
$(19)$ & 0 & 415 \\
$(20)$ & 0 & 415 \\
\hline
\end{tabular}

\section{Note on the System}

You can imagine yourself at one of the two locations with an inventory of that location's currency. Should you find it advantageous, you could buy the currency of the other location and use it to buy X and/or Y there instead of buying $\mathrm{X}$ and/or $\mathrm{Y}$ at your location.

\section{References}

Benninga, Simon, and Protopapadakis, Aris A. "The Equilibrium Pricing of Exchange Rates and Assets When Trade Takes Time." J. Internat. Money and Finance 7 (June 1988): 129-49.

Goodwin, Barry K.; Grennes, Thomas; and Wohlgenant, Michael K. "Testing the Law of One Price When Trade Takes Time." J. Internat. Money and Finance 9 (March 1990): 21-40.

Grilli, Vittorio, and Roubini, Nouriel. "Liquidity and Exchange Rates." $J$. Internat. Econ. 32 (May 1992): 339-52.

Kimbrough, Kent P. "International Linkages, Exchange-Rate Regimes, and the International Transmission Process: Perspectives from Optimizing Models." In International Economics, edited by Lawrence H. Officer. Boston: Kluwer, 1987.

Krugman, Paul, and Obstfeld, Maurice. International Economics: Theory and Policy. 3d ed. New York: HarperCollins, 1994.

Lucas, Robert E., Jr. "Interest Rates and Currency Prices in a Two-Country World." J. Monetary Econ. 10 (November 1982): 335-59. 
Meese, Richard A., and Rogoff, Kenneth S. "Empirical Exchange Rate Models of the Seventies: Do They Fit out of Sample?" J. Internat. Econ. 14 (February 1983): 3-24

Noussair, Charles N.; Plott, Charles R.; and Riezman, Raymond G. " An Experimental Investigation of the Patterns of International Trade." A.E.R. 85 (June 1995): 462-91.

Plott, Charles R. "A Computerized Laboratory Market System and Research Support Systems for the Multiple Unit Double Auction.'” Social Science Working Paper no. 783. Pasadena: California Inst. Tech., 1991.

Sargent, Thomas J. Dynamic Macroeconomic Theory. 2d ed. Cambridge, Mass.: Harvard Univ. Press, 1987.

Smith, Vernon L., and Williams, Arlington W. "The Effects of Rent Asymmetries in Experimental Auction Markets." J. Econ. Behavior and Organization 3 (March 1982): 99-116.

White, Halbert. "A Heteroskedasticity-Consistent Covariance Matrix Estimator and a Direct Test for Heteroskedasticity." Econometrica 48 (May 1980): 817-38. 